\title{
Neuraxial anesthesia and bladder dysfunction in the perioperative period: a systematic review
}

\section{Anesthésie neuraxiale et dysfonction vésicale en période périopératoire: une revue systématique}

\author{
Stephen Choi, MD • Padraig Mahon, MD • \\ Imad T. Awad, MBChB
}

Received: 11 November 2011/ Accepted: 13 April 2012/Published online: 26 April 2012

(C) Canadian Anesthesiologists' Society 2012

\begin{abstract}
Purpose Urinary retention requiring catheterization carries the risk of infection. Neuraxial anesthesia causes transient impairment of bladder function ranging from delayed initiation of micturition to frank urinary retention. We undertook a review of the literature to determine the elements of neuraxial anesthesia and analgesia that prolong bladder dysfunction and increase the incidence of urinary retention.

Methods We performed a systematic search of the PubMed, MEDLINE, and EMBASE databases (from January 1980 to January 2011) to identify studies where neuraxial anesthesia and/or analgesia were employed and at least one of the following outcomes was reported: urinary retention, time to micturition, or post void residual. We included randomized controlled trials and observational studies published in the English language and we excluded case reports. The randomized trials were graded according to the Jadad score.
\end{abstract}

Principal findings Our search yielded 94 studies, and in 16 of these studies, the authors reported time to micturition

\begin{abstract}
Author contributions Imad Awad is the senior responsible author who conceived this project. Stephen Choi had primary responsibility for preparing the manuscript, and Padraig Mahon had a significant role in preparing the manuscript. Stephen Choi and Padraig Mahon performed the literature search, and Stephen Choi, Padraig Mahon, and Imad Awad reviewed the studies.
\end{abstract}

S. Choi, MD - I. T. Awad, MBChB (ه)

Department of Anesthesia, Sunnybrook Health Sciences Centre, University of Toronto, 2075 Bayview Avenue, Toronto,

ON M4N 3M5, Canada

e-mail: imad.awad@sunnybrook.ca

P. Mahon, MD

Department of Anaesthesia and Intensive Care Medicine, Cork University Hospital, University College Cork, Cork, Ireland after intrathecal anesthesia of varying local anesthetics and doses. Intrathecal injections were performed in 41 of these studies, epidural anesthesia/analgesia was used in 39 studies, and five studies involved both the intrathecal and epidural routes. Meta-analysis was not possible because of the heterogeneity of interventions and reported outcomes. The duration of detrusor dysfunction after intrathecal anesthesia is correlated with local anesthetic dose and potency. The incidence of urinary retention displays a similar trend and is further increased by the presence of neuraxial opioids, particularly long-acting variants. Urinary tract infection secondary to catheterization occurred rarely.

Conclusions Neuraxial anesthesia/analgesia results in transient detrusor dysfunction. The duration of dysfunction depends on the potency and dose of medication used; however, it does not appear to result in significant morbidity.

\section{Résumé}

Objectif Une rétention urinaire nécessitant un cathétérisme s'accompagne $d u$ risque d'infection. L'anesthésie neuraxiale provoque un trouble transitoire de la fonction vésicale allant du début retardé de la miction à la rétention urinaire franche. Nous avons entrepris une revue de la littérature pour déterminer les éléments de l'anesthésie et de l'analgésie neuraxiales qui prolongent la dysfonction vésicale et augmentent l'incidence de la rétention urinaire.

Méthodes Nous avons effectué une recherche systématique dans les bases de données PubMed, MEDLINE et EMBASE (de janvier 1980 à janvier 2011) pour identifier des études dans lesquelles une anesthésie et/ou une analgésie neuraxiales ont été employées avec la description d'au moins l'un des résultats suivants: rétention urinaire, retard de miction, volume résiduel post mictionnel. Nous avons inclus 
les essais randomisés contrôlés et les études observationnelles publiées en anglais et avons exclu les comptes rendus de cas. Les essais randomisés ont été cotés selon le score de Jadad. Constatations principales Notre recherche a rassemblé 94 études et des retards de miction ont été décrits par les auteurs dans 16 de ces études, après anesthésie intrathécale avec différents anesthésiques locaux à des posologies variables. Des injections intrathécales ont été réalisées dans 41 de ces études; une anesthésielanalgésie épidurale a été utilisée dans 39 études; et les deux voies (intrathécale et épidurale) ont été utilisées dans cinq études. Une méta-analyse n'a pas été possible en raison de l'hétérogénéité des interventions et des résultats décrits. La durée des troubles dysfonctionnels du détrusor après anesthésie intrathécale est corrélée à la dose et à la puissance de l'anesthésique local. L'incidence de la rétention urinaire affiche une tendance comparable et est encore augmentée par la présence neuraxiale de morphiniques, en particulier de leurs formes à longue durée d'action. Les infections des voies urinaires après un cathétérisme ont été rares.

Conclusions L'anesthésielanalgésie neuraxiale entraîne une dysfonction transitoire du détrusor. La durée des troubles fonctionnels dépend de la puissance et de la posologie du médicament utilisé; toutefois, cela ne semble pas se traduire par une morbidité significative.

Neuraxial anesthesia can result in significant bladder denervation in the perioperative period and can subsequently precipitate urinary retention. ${ }^{1}$ The dysfunction associated with this transient effect ranges from mild (with delayed initiation of micturition and incomplete bladder emptying) to severe (with urinary retention and bladder overdistension). When alleviated with catheterization, urinary retention can increase morbidity by introducing infection and increasing the length of hospital stay. ${ }^{2-5}$

Urinary retention is the inability to initiate micturition or to empty the bladder completely. There are no clear defining characteristics of urinary retention, such as a specific volume of urine or elapsed time postoperatively without micturition; however, in accordance with the consensus view in the contemporary literature, urinary retention would be described as an inability to initiate micturition with a bladder volume exceeding $500 \mathrm{~mL} .^{6}$ Urinary retention can be complete or partial, acute or chronic, painful or silent, obstructive or non-obstructive. "Overflow" incontinence secondary to excess intravesical pressure can occur. De novo incontinence secondary to sphincter damage, detrusor overactivity (urgency), or stress (precipitated by increased intra-abdominal pressure) developing in the perioperative period are uncommon occurrences. The long-term consequences of postoperative urinary retention (POUR) are not always immediately apparent in the perioperative period, although increased hospital length of stay and prolonged detrusor dysfunction have been documented. ${ }^{1,6}$

Neuraxial local anesthetics block the afferent and efferent limbs of the micturition reflex resulting in detrusor dysfunction and the inability to sense a full bladder, thus impairing micturition. Neuraxial opioids enhance this effect by decreasing the sensation of bladder fullness, thus increasing bladder capacity and weakening detrusor contraction through their actions at the spinal level and in the pontine micturition centre. $^{7-9}$ Other previously identified perioperative and preexisting risk factors for urinary retention include age, type of surgery, drug side effects, and benign prostatic hypertrophy, but none usually results in the transient, though dense, dysfunction caused by neuraxial anesthesia.

This study was initiated because a recent review on urinary retention did not focus specifically on urinary retention after neuraxial anesthesia and/or analgesia. ${ }^{1}$ The extensive work by Baldini et al. is a narrative review wherein they aim to give the reader a broad overview of the clinical problem. ${ }^{1}$ In the present study, we attempt to go beyond a narrative review and perform a systematic assessment of urinary outcomes, including time to micturition, incidence of catheterization, and subsequent frequency of urinary tract infection after neuraxial intervention. The primary aim of this review is to determine the incidence of urinary retention and any associated morbidity in patients following neuraxial anesthesia or analgesia and to identify risk factors prolonging impaired micturition.

\section{Methods}

A systematic search of the PubMed, MEDLINE, and EMBASE databases was performed from January 1980 to January 2011 using the medical subject heading (MeSH) words "neuraxial anesthesia" or "neuraxial analgesia" or "epidural" or "intrathecal" or "spinal". These were combined with the MeSH terms "urinary retention" or "urinary incontinence" or "urinary catheterization" or "micturition" or "post void residual". The search was limited to articles published in the English language and human adults. Each abstract was evaluated to identify studies where neuraxial anesthesia was utilized and urinary retention, or time to micturition, or post void residual was reported as an outcome. The references of the retrieved articles were hand searched for any relevant studies not captured in the original search. In addition to randomized controlled trials (RCTs), observational studies were also included because of the limited amount of data present in the literature. 
Studies included in the review were categorized according to modality of neuraxial anesthesia - intrathecal or epidural. Studies involving combined spinal-epidural techniques were grouped with those utilizing epidural techniques because the effects of the epidural infusion typically outlast the effects of the intrathecal component. Studies were included even if patients did not undergo surgical procedures but were volunteers for urodynamic studies. Data were abstracted using a template created independently to identify the following information: primary author with year of publication, study design, Jadad score for RCTs, number of patients, surgical class, neuraxial medication employed (local anesthetic only, local anesthetic with short- or long-acting opioid, opioid only, undefined), incidence of urinary retention, average time to first micturition, and post void residual (PVR). If reported in the source study, we also abstracted the number of patients requiring catheterization and the incidence of urinary tract infection. Where possible, we reported the statistical significance for the incidence of urinary retention between comparators.

With each neuraxial technique, studies were further subdivided into the following categories: local anesthetic only, local anesthetic with long-acting opioid, local anesthetic with short-acting opioid, and undefined.

The methodology of each RCT was graded according to the criteria published by Jadad et al. ${ }^{10}$ All RCTs were included regardless of grade, and observational studies were not graded because it became clear after the initial literature review that the level of methodological rigour and study methods were so variable that meta-analysis would not be feasible or appropriate given that there is no easily communicated standard for grading observational studies. Two of the authors (S.C., P.M.) independently performed the literature search and data extraction. Results were combined and differences were resolved through discussion amongst the three authors (S.C., P.M., I.A.).

\section{Results}

Initially, 4,465 references were retrieved, and the search yielded 3,662 abstracts when limited to the English language and human subjects. Each abstract was reviewed, but it was not utilized if it did not state clearly that urinary retention, or PVR, or time to micturition was recorded as an outcome. If the abstract did not state specifically that spinal/epidural anesthesia and/or analgesia were employed, it was not retained.

We identified 94 studies (11,162 patients) where neuraxial anesthesia or analgesia was employed and where urinary retention, time to micturition, or PVR was reported as an outcome (Figure). Meta-analysis was not performed owing to the heterogeneity of the definitions of urinary retention, if at all

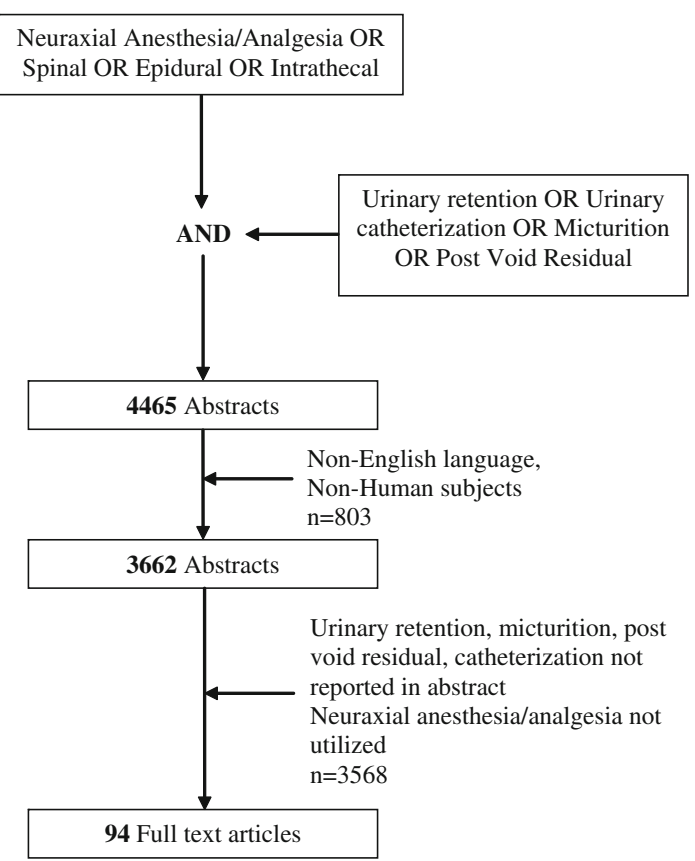

Figure Flow chart of screened, excluded, and included studies

provided, and the significant variability in the dose, type, and use of opioids in the neuraxial medications utilized.

In 16 of the 94 RCTs (1,066 patients), time to return of spontaneous micturition after intrathecal anesthesia was assessed as a primary outcome (Table 2). ${ }^{11-26}$ In 41 studies (5,548 patients), urinary retention or PVR with intrathecal anesthesia was assessed (Table 3), 11,13,16,17,20,22,27-65 and in 39 studies (4,938 patients), urinary retention or PVR with epidural anesthesia and/or analgesia was assessed (Table 4). ${ }^{28,33,35,43,48-50,54,66-100}$ An additional five studies involved both intrathecal and epidural techniques. There is overlap in the numbers of patients/studies reported for Tables 2, 3, and 4 because multiple outcomes and/or multiple neuraxial procedures were examined in several studies. The characteristics of the included studies are detailed in Table 1. Among the 94 studies, 54 of the included studies were RCTs, 27 were prospective observational studies, and 13 were retrospective reviews. None of the included studies designated urinary retention as a primary outcome measure. Among the 94 studies, two studies investigated spinal anesthesia in volunteers with no surgical procedure performed. ${ }^{15,24}$

Of the 55 studies (including 16 RCTs in Table 2) reporting a urologic outcome after intrathecal anesthesia, 41 specifically assessed the incidence of urinary retention, 27 assessed for rate of catheterization, 16 assessed time to micturition, six reported rates of infection, and one reported PVR. Only 25 studies defined criteria for urinary retention. The criteria ranged from quoting bladder volumes (from $150-600 \mathrm{~mL}$ ) or time frames (from $30 \mathrm{~min}$ to two days) to 
Table 1 Characteristics of the 94 studies retained for analysis

\begin{tabular}{|c|c|c|}
\hline & Number $(n)$ & Percentage $(\%)$ \\
\hline \multicolumn{3}{|l|}{ Study type } \\
\hline Randomized trial & 54 & 57 \\
\hline Observational study & 27 & 29 \\
\hline Retrospective review & 13 & 14 \\
\hline \multicolumn{3}{|l|}{ Jadad score (for RCTs) } \\
\hline 5 & 16 & 30 \\
\hline 4 & 3 & 6 \\
\hline 3 & 25 & 46 \\
\hline 2 & 5 & 9 \\
\hline 1 & 5 & 9 \\
\hline \multicolumn{3}{|l|}{ Type of neuraxial procedure } \\
\hline Spinal only & 51 & 54 \\
\hline Epidural only & 39 & 41 \\
\hline Both spinal and epidural & 5 & 5 \\
\hline \multicolumn{3}{|l|}{ Urologic outcome reported* } \\
\hline Urinary retention & 79 & 84 \\
\hline Time to micturition & 25 & 28 \\
\hline Post void residual & 4 & 5 \\
\hline Catheterization & 64 & 68 \\
\hline Urinary tract infection & 13 & 14 \\
\hline \multicolumn{3}{|c|}{ Urologic outcome as primary outcome } \\
\hline Urinary retention & 0 & 0 \\
\hline Time to micturition & 16 & 17 \\
\hline Post void residual & 0 & 0 \\
\hline \multicolumn{3}{|l|}{ Urinary Retention } \\
\hline Defined & 43 & 46 \\
\hline Undefined & 37 & 39 \\
\hline Not applicable & 14 & 15 \\
\hline \multicolumn{3}{|l|}{ Neuraxial medication type/dose } \\
\hline Reported & 74 & 79 \\
\hline Local anesthetic only & 35 & 47 \\
\hline Local anesthetic + Opioid & 31 & 43 \\
\hline Opioid only & 9 & 10 \\
\hline Not Reported & 20 & 21 \\
\hline \multicolumn{3}{|l|}{ Number of subjects } \\
\hline$<50$ & 42 & 44 \\
\hline $51-100$ & 31 & 35 \\
\hline $101-150$ & 8 & 8 \\
\hline $151-200$ & 7 & 7 \\
\hline$>200$ & 6 & 6 \\
\hline
\end{tabular}

$n=$ number of studies; $\mathrm{RCT}=$ randomized controlled trial; $*$ Due to instances where multiple urologic outcomes were reported, some studies were counted more than once

stating that catheterization was necessary without describing indications or that urinary retention was simply as inability to void without other defining criteria (Table 3 ).

Forty-two of the 44 studies reporting a urologic outcome after epidural analgesia specifically assessed the incidence of urinary retention. Similarly, only 26 studies defined criteria for urinary retention, but these criteria were as varied as those in the studies reporting intrathecal anesthesia. Thirty-one studies reported catheterization rates, seven reported infection rates, and only one reported PVR.

Local anesthetic type and dose

The incidence of POUR appears correlated with the specific intrathecal local anesthetic utilized. The studies reporting incidence rates of $>20 \%$ were those utilizing either tetracaine or bupivacaine, while those employing procaine or lidocaine reported incidence rates $<20 \%$ (Table 3). The studies utilizing epidural analgesia are difficult to assess in this respect because of the highly variable durations of infusion (Table 4).

The 16 RCTs that specifically examined time to return of spontaneous micturition after intrathecal anesthesia as a primary outcome assessed several local anesthetics in differing concentrations, densities, and doses (Table 2). The time to first micturition varied from $103 \mathrm{~min}^{15}$ (2-chloroprocaine) to $462 \mathrm{~min}$ (bupivacaine). ${ }^{18} \mathrm{We}$ did not perform a linear regression analysis of the micturition time based on dose because we considered that the varying densities and concentrations utilized would confound the results. Seeing as widely varying doses, concentrations, and densities were utilized even within groups, we did not combine the results of each local anesthetic.

Time to spontaneous micturition correlates with the potency of the local anesthetic administered intrathecally, and it correlates with dose for each specific local anesthetic. Kamphuis et al. showed this with filling cystometric studies comparing bupivacaine with lidocaine. ${ }^{18}$ The longer lasting and more potent bupivacaine was associated with longer detrusor dysfunction (462 min) compared with lidocaine $(233 \mathrm{~min})$. This difference becomes more apparent when varying doses of the same medication (concentration and density) are compared within studies. Ben-David et al., Urmey et al., Kallio et al., and Casati et al. showed this with bupivacaine, lidocaine, articaine, and 2-chloroprocaine, respectively. ${ }^{11,22,25,26}$ The longest times to spontaneous micturition after intrathecal anesthesia with each of bupivacaine, lidocaine, articaine, and 2-chloroprocaine were $462 \mathrm{~min}, 260 \mathrm{~min}, 279 \mathrm{~min}$, and 271 min, respectively. ${ }^{18,19,21,26}$

\section{Neuraxial opioids}

The effects of intrathecal or epidural opioids on bladder function are similar to those of local anesthetics in that the potency and dose of the opioid appears to predict the duration of bladder dysfunction. Morphine in conjunction with intrathecal anesthesia was utilized in only two studies, 
Table 2 Studies with time to micturition as an outcome after intrathecal local anesthetics

\begin{tabular}{lllllll}
\hline $\begin{array}{l}\text { Intrathecal Drug Type } \\
\text { and Author/Year }\end{array}$ & $\begin{array}{l}\text { Drug Dose } \\
(\mathrm{mg})\end{array}$ & Concentration & Baricity & $\begin{array}{l}\text { Number of } \\
\text { Patients }\end{array}$ & Opioid & $\begin{array}{l}\text { Time (min) to } \\
\text { Micturition } \\
\text { Mean (SD) }\end{array}$ \\
\hline
\end{tabular}

Total (1,066 patients)

Bupivacaine (368 patients)

\begin{tabular}{|c|c|c|c|c|c|c|c|}
\hline \\
\hline Dijkstra $2008^{14}$ & 15 & $0.5 \%$ & Iso & 38 & - & 350 (N/A) & N/A \\
\hline Ben-David $1996^{11}$ & 15 & $0.5 \%$ & Hyper & 15 & - & $428(34)$ & N/A \\
\hline Ben-David $1996^{11}$ & 10 & $0.33 \%$ & Hyper & 15 & - & $241(14)$ & N/A \\
\hline Kamphuis $2008^{18}$ & 10 & $0.75 \%$ & Hyper & 10 & - & $462(61)$ & N/A \\
\hline Lacasse $2011^{21}$ & 7.5 & $0.75 \%$ & Hyper & 53 & - & $338(99)$ & N/A \\
\hline Gupta $2003^{16}$ & 7.5 & $0.5 \%$ & Hyper & 20 & Fent $25 \mu \mathrm{g}$ & 335 (N/A) & $4 / 20$ \\
\hline Yoos $2005^{24}$ & 7.5 & $0.5 \%$ & Iso & 8 & - & 191(32) & N/A \\
\hline Ben-David $1996^{11}$ & 7.5 & $0.25 \%$ & Hyper & 15 & - & $186(14)$ & N/A \\
\hline Gupta $2003^{16}$ & 6 & $0.5 \%$ & Hyper & 20 & Fent $25 \mu \mathrm{g}$ & 268 (N/A) & $3 / 20$ \\
\hline Valanne $2001^{23}$ & 6 & $0.5 \%$ & Hyper & 51 & - & 203 (N/A) & N/A \\
\hline Kuusniemi $2000^{20}$ & 6 & $0.5 \%$ & Hyper & 30 & - & $228(60)$ & N/A \\
\hline Kuusniemi $2000^{20}$ & 6 & $0.5 \%$ & Iso & 30 & - & $252(60)$ & N/A \\
\hline Ben-David $1996^{11}$ & 5 & $0.16 \%$ & Hyper & 15 & - & $163(8)$ & N/A \\
\hline Valanne $2001^{23}$ & 4 & $0.5 \%$ & Hyper & 48 & - & $172(\mathrm{~N} / \mathrm{A})$ & N/A \\
\hline \multicolumn{8}{|c|}{ L-bupivacaine (30 patients) } \\
\hline Breebaart $2003^{13}$ & 10 & $0.33 \%$ & Iso & 30 & - & $284(57)$ & $1 / 30$ \\
\hline \multicolumn{8}{|c|}{ Ropivicaine (30 patients) } \\
\hline Breebaart $2003^{13}$ & 10 & $0.5 \%$ & Iso & 30 & - & $285(65)$ & $1 / 30$ \\
\hline \multicolumn{8}{|c|}{ Lidocaine (315 patients) } \\
\hline Kamphuis $2008^{18}$ & 100 & $2 \%$ & Hyper & 10 & Sufent $20 \mu \mathrm{g}$ & $332(52)$ & N/A \\
\hline Kamphuis $2008^{18}$ & 100 & $2 \%$ & Hyper & 10 & - & $233(31)$ & N/A \\
\hline Urmey $1995^{22}$ & 80 & $2 \%$ & Iso & 29 & - & $215(73)$ & N/A \\
\hline Breebaart $2003^{13}$ & 60 & $2 \%$ & Iso & 30 & - & $245(65)$ & $0 / 30$ \\
\hline Urmey $1995^{22}$ & 60 & $2 \%$ & Iso & 32 & - & $193(30)$ & N/A \\
\hline Ben-David $2000^{12}$ & 50 & $1 \%$ & Нypo & 55 & - & $200(102)$ & N/A \\
\hline Urmey $1995^{22}$ & 40 & $2 \%$ & Iso & 29 & - & $159(36)$ & N/A \\
\hline Kawamata $2003^{19}$ & 30 & $3 \%$ & Hyper & 32 & - & $260(\mathrm{~N} / \mathrm{A})$ & N/A \\
\hline Kawamata $2003^{19}$ & 30 & $1 \%$ & Hyper & 33 & - & $200(\mathrm{~N} / \mathrm{A})$ & N/A \\
\hline Ben-David $2000^{12}$ & 20 & $1 \%$ & Нyро & 55 & Fent $25 \mu \mathrm{g}$ & $188(87)$ & N/A \\
\hline \multicolumn{8}{|c|}{ Prilocaine (36 patients) } \\
\hline Hendriks $2009^{17}$ & 50 & $2 \%$ & Iso & 36 & - & $227(45)$ & $2 / 36$ \\
\hline \multicolumn{8}{|c|}{ Articaine (165 patients) } \\
\hline Kallio $2006^{26}$ & 100 & $4 \%$ & Hyper & 30 & - & 279 (N/A) & N/A \\
\hline Dijkstra $2008^{14}$ & 100 & $5 \%$ & Hyper & 39 & - & 257 (N/A) & N/A \\
\hline Kallio $2006^{26}$ & 84 & $4 \%$ & Hyper & 30 & - & 271 (N/A) & N/A \\
\hline Kallio $2006^{26}$ & 60 & $4 \%$ & Hyper & 30 & - & 249 (N/A) & N/A \\
\hline Hendriks $2009^{17}$ & 36 & $2 \%$ & Iso & 36 & - & $184(39)$ & $1 / 36$ \\
\hline \multicolumn{8}{|c|}{ 2-Chloroprocaine (114 patients) } \\
\hline Casati $2006^{25}$ & 50 & $2 \%$ & Iso & 15 & - & 203 (N/A) & N/A \\
\hline Lacasse $2011^{21}$ & 40 & $2 \%$ & Iso & 53 & - & $271(87)$ & N/A \\
\hline Yoos $2005^{24}$ & 40 & $2 \%$ & Iso & 8 & - & $113(14)$ & N/A \\
\hline Casati $2006^{25}$ & 40 & $2 \%$ & Iso & 15 & - & $198(\mathrm{~N} / \mathrm{A})$ & N/A \\
\hline Casati $2006^{25}$ & 30 & $2 \%$ & Iso & 15 & - & $182(\mathrm{~N} / \mathrm{A})$ & N/A \\
\hline Gonter $2005^{15}$ & 30 & $1.5 \%$ & Hyper & 8 & - & $103(12)$ & N/A \\
\hline
\end{tabular}


Table 2 continued

\begin{tabular}{|c|c|c|c|c|c|c|c|}
\hline $\begin{array}{l}\text { Intrathecal Drug Type } \\
\text { and Author/Year }\end{array}$ & $\begin{array}{l}\text { Drug Dose } \\
(\mathrm{mg})\end{array}$ & Concentration & Baricity & $\begin{array}{l}\text { Number of } \\
\text { Patients }\end{array}$ & Opioid & $\begin{array}{l}\text { Time }(\min ) \text { to } \\
\text { Micturition } \\
\text { Mean (SD) }\end{array}$ & $\begin{array}{l}\text { Required } \\
\text { catheterization }\end{array}$ \\
\hline \multicolumn{8}{|l|}{ Procaine ( 8 patients) } \\
\hline Gonter $2005^{15}$ & 80 & $4 \%$ & Hyper & 8 & - & $156(23)$ & N/A \\
\hline
\end{tabular}

Fent $=$ fentanyl; Hyper $=$ hyperbaric $;$ Hypo $=$ hypobaric; Iso $=$ isobaric; N/A $=$ not available; SD $=$ standard deviation; Sufent $=$ sufentanil

both non-randomized, and the reported incidence rates of urinary retention were $36 \%$ and $25 \%$, respectively. ${ }^{45,64}$ In contrast, studies in which either intrathecal fentanyl or sufentanil was utilized reported lower incidence rates ranging from 0 to $25 \%{ }^{12,16,18,46,48,57,61}$ Kamphuis et al. showed that the addition of sufentanil $20 \mu \mathrm{g}$ prolonged the detrusor dysfunction associated with intrathecal lidocaine $100 \mathrm{mg}$ from 233 to 332 min. $^{18}$

A similar pattern occurred with neuraxial opioids and epidural analgesia, though the pattern is less distinct (Table 4). Ten studies utilizing long-acting opioids reported incidence rates of $9.2-79.5 \%$ (only three studies showed rates $<40 \%$ ). In 15 studies on short-acting opioids, the rate of urinary retention ranged from $0 \%$ to $40 \%$.

Comparison with other anesthetic modalities

Only five studies made comparisons with other anesthetic modalities. Schmittner et al. compared intrathecal with general anesthesia and found no difference in time to micturition. ${ }^{56}$ Casati et al. also found no difference between intrathecal, general, or peripheral nerve block anesthesia in terms of time to micturition. ${ }^{25}$ Sungurtekin et al. found no difference between intrathecal anesthesia and local infiltration, while van Veen et al., Young et al., and Anannamchareon et al. reported significantly higher rates of urinary retention with intrathecal anesthesia compared with local infiltration. ${ }^{27,58,61,63}$

\section{Urinary tract infection}

Thirteen of the 94 studies included in this review reported the incidence of urinary tract infection associated with catheterization. ${ }^{28,30,40,61,63,64,66,69,73,75,76,89,100}$ Six of these reported no infections while seven studies reported rates of $<10 \%$.

\section{Discussion}

Our review of the literature identified several themes with respect to the effects of neuraxial anesthesia and analgesia on POUR and other urinary outcomes. First, the potency/ dose of local anesthetic and the presence of opioids affect detrusor dysfunction and the time to return of spontaneous micturition. This time period lasts as long as $462 \mathrm{~min}$ (bupivacaine) or is as short as $103 \mathrm{~min}$ (2-chloroprocaine). With long-acting epidural opioids, the reported incidence of urinary retention is as high as $79.5 \%$. Second, whether detrusor dysfunction specifically results in POUR is unclear, but the incidence of POUR, at least after singledose intrathecal anesthesia, is low, and complications, such as urinary tract infections, are even less frequent. Complications (urinary tract infection) associated with POUR after epidural analgesia also surface infrequently. However, there are inherent limitations to our analysis. Few of the included studies are randomized trials that compare general with neuraxial anesthesia and include urinary retention as a primary outcome. Furthermore, we included all RCTs regardless of Jadad score and did not grade observational studies to highlight the inadequacy of the current evidence with methodologically sound studies assessing this clinical issue. Indeed, the heterogeneity of definitions and anesthetic management further hampers any ability to offer more quantitative analysis.

Our conclusions must be viewed cautiously owing to several factors, including the aforementioned varying definitions used by the included studies to define urinary retention and the significant heterogeneity in local anesthetic type/dose and opioid doses. Several studies, though implicating intrathecal anesthesia as a risk factor for urinary retention, neither discuss a comparative anesthetic modality nor provide the dose/type of local anesthetic utilized. $28,30,33,36,41,43,52-55$

Results of studies assessing the urodynamic effects of both intrathecal local anesthetics and opioids tend to concur with our data. Kamphuis et al. performed filling cystometric studies in 30 male patients to estimate detrusor pressure and flow rates. ${ }^{18}$ The studies were performed both prior to and following intrathecal anesthesia with hyperbaric lidocaine $(100 \mathrm{mg})$ with or without sufentanil $(20 \mu \mathrm{g})$ or with hyperbaric bupivacaine $(10 \mathrm{mg})$. Patients' bladders were filled at a constant rate of $50 \mathrm{~mL} \bullet \mathrm{min}^{-1}$ when supine, and filling was stopped when a strong desire to void was felt (the cystometric capacity $\sim 500 \mathrm{~mL}$ ). The urge to void disappeared within $60 \mathrm{sec}$ of the start of injection of intrathecal anesthetic. The recovery of the ability to void normally (using only detrusor muscle, generating 


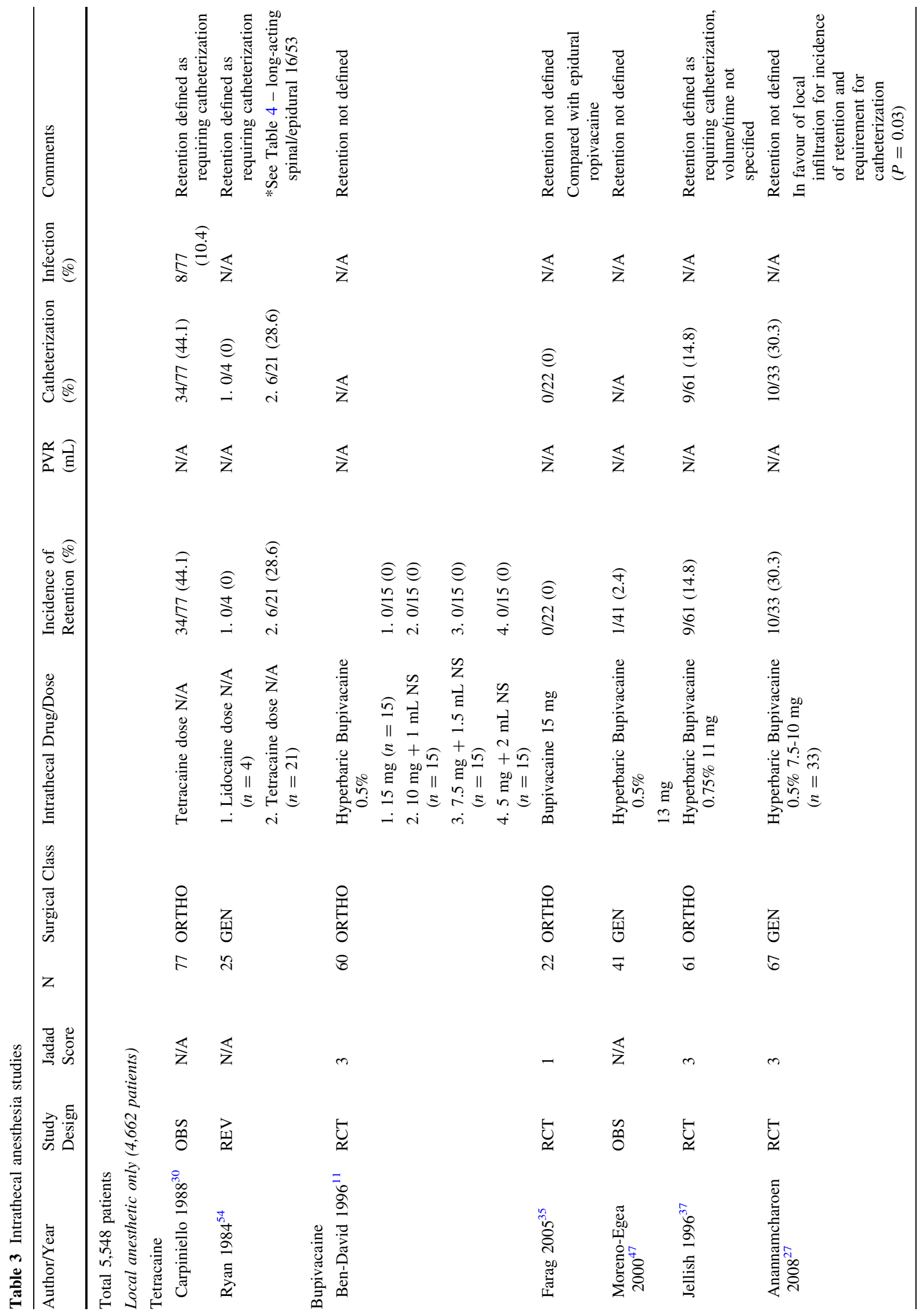




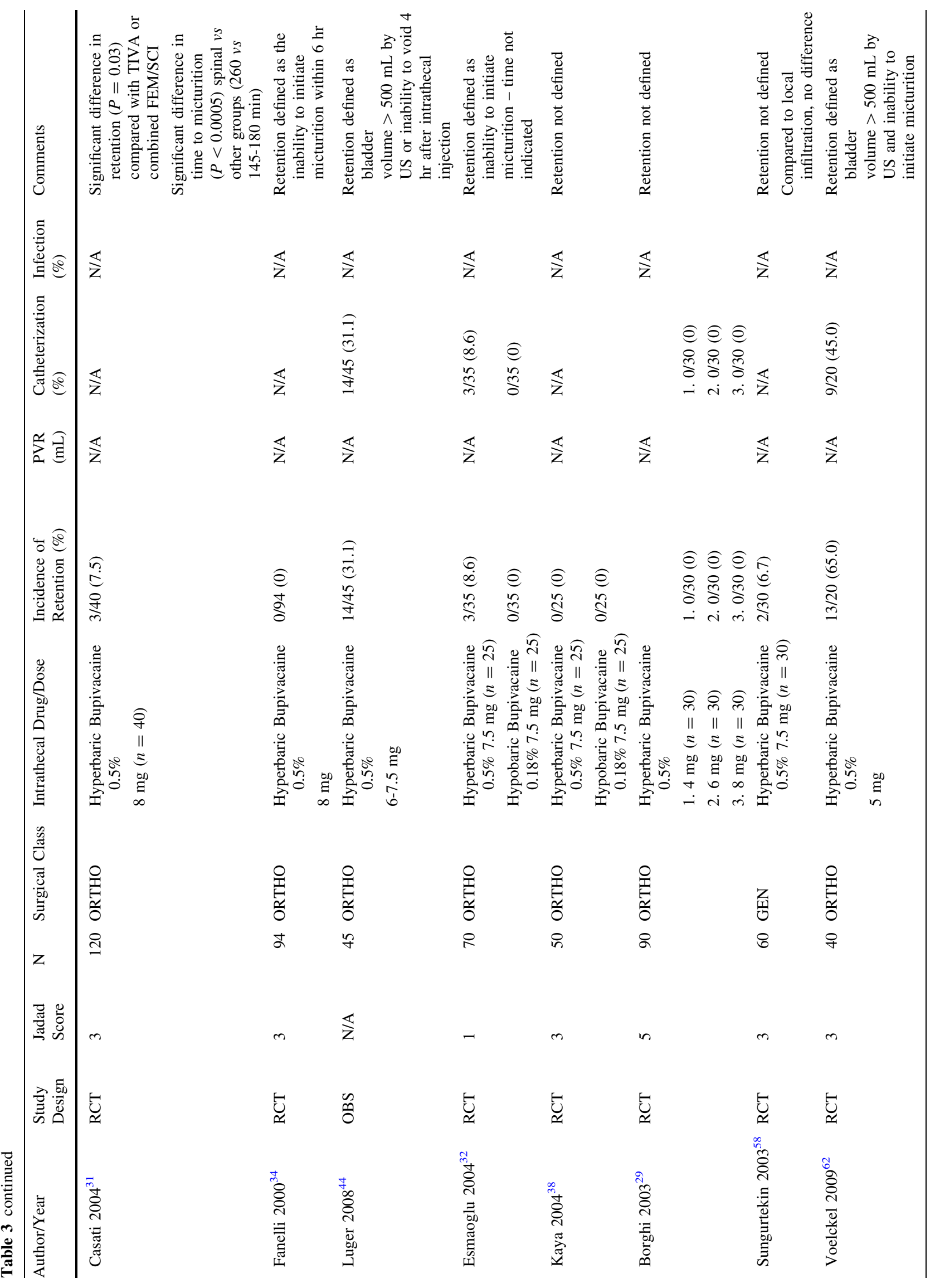




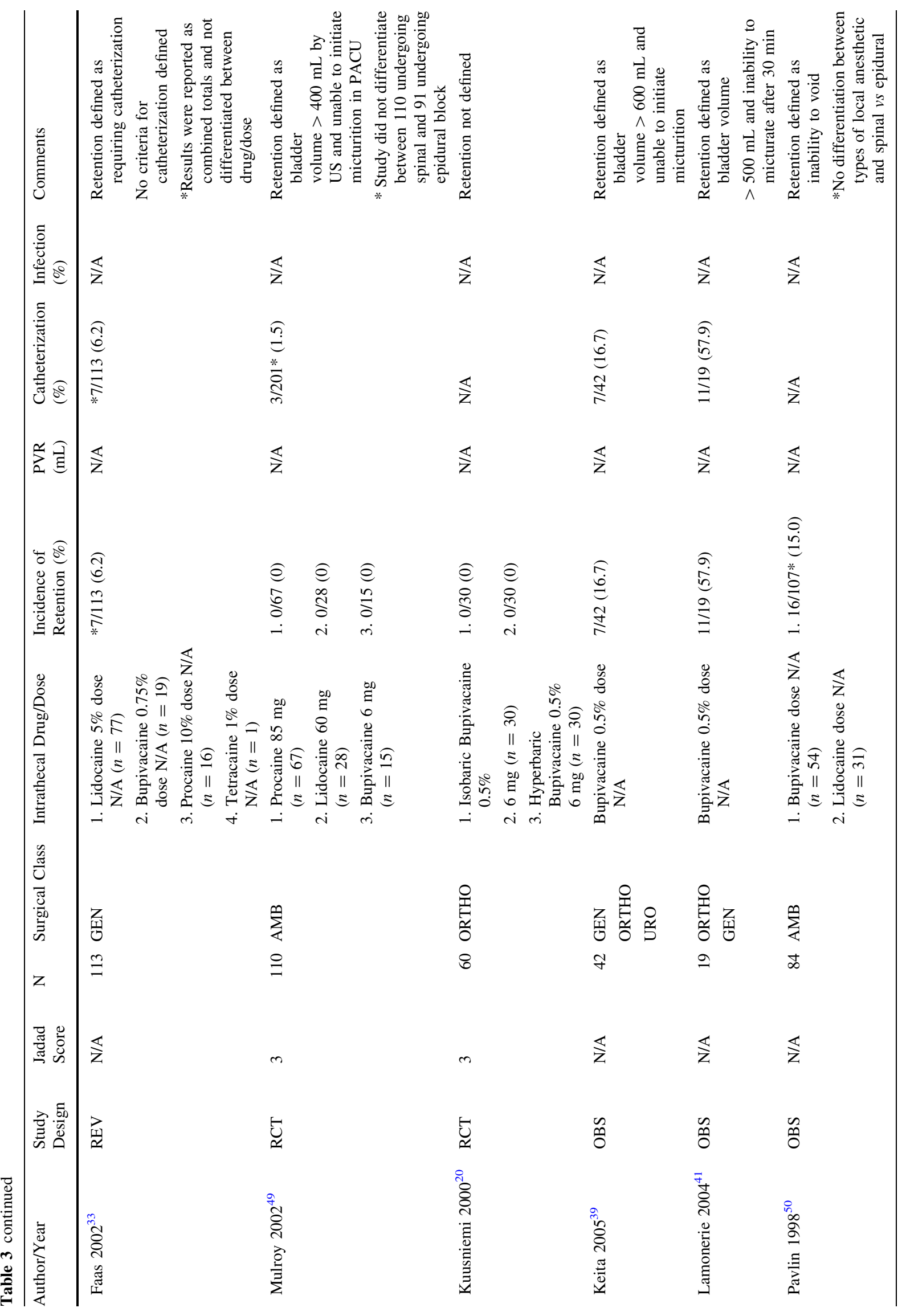




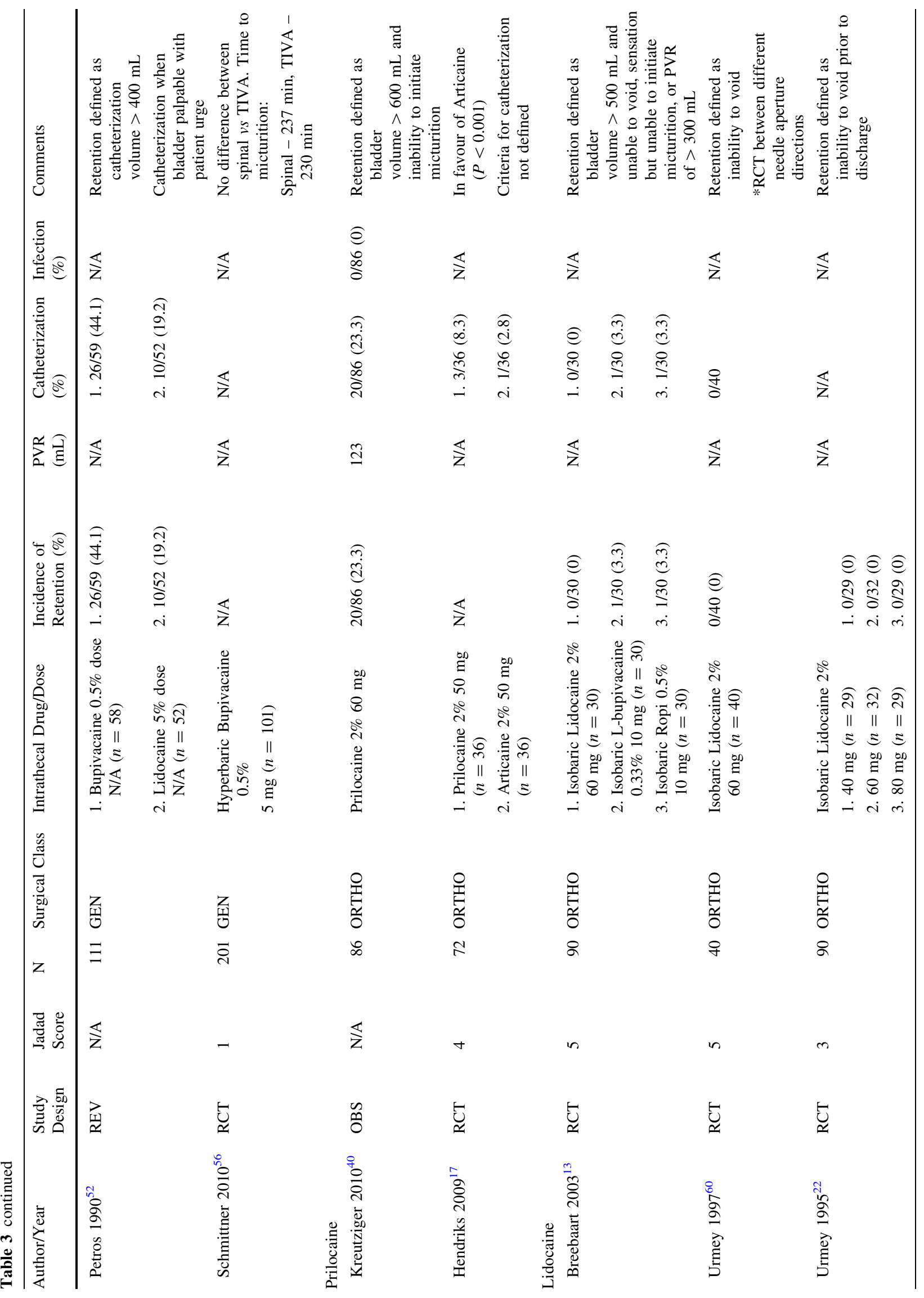




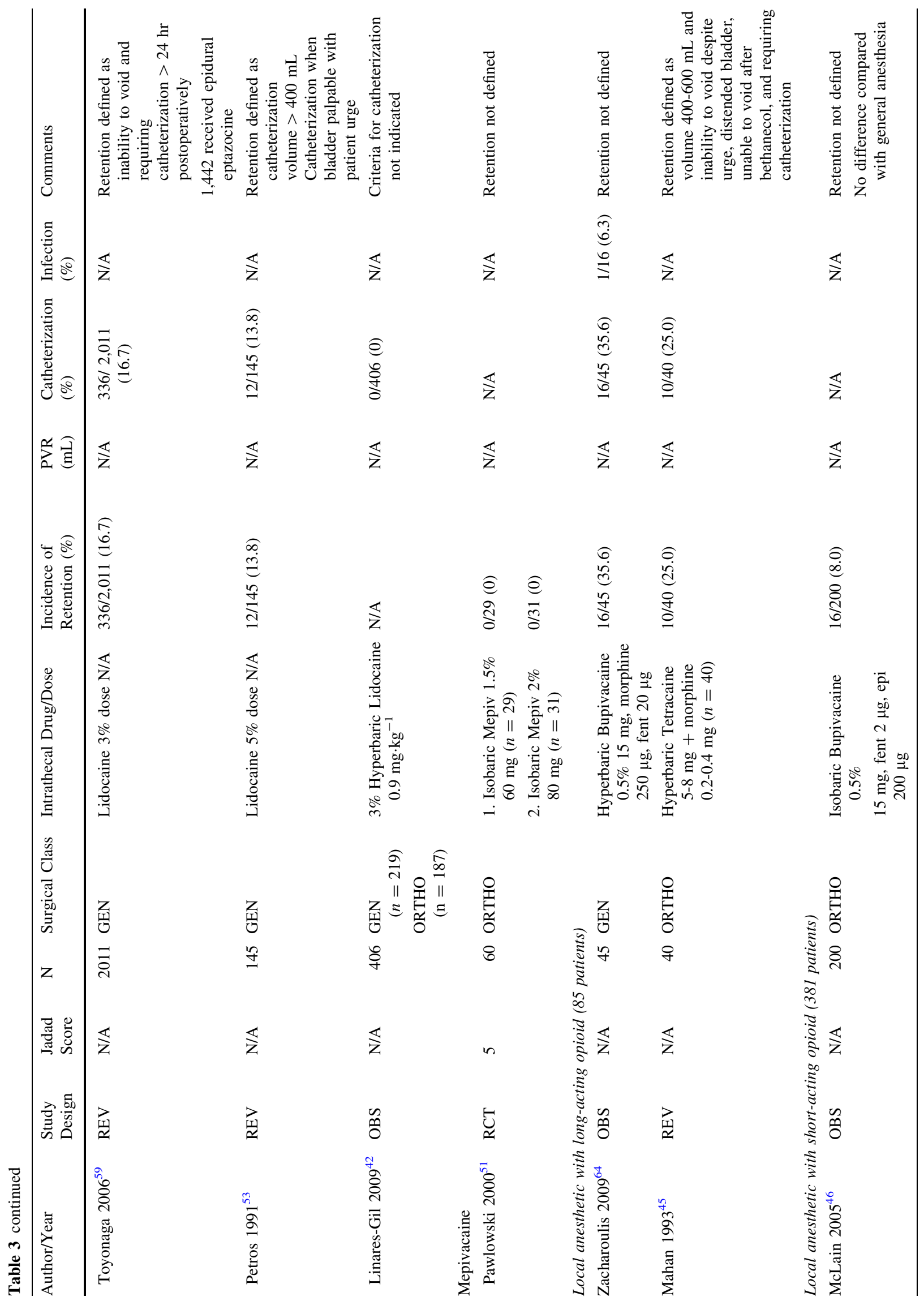




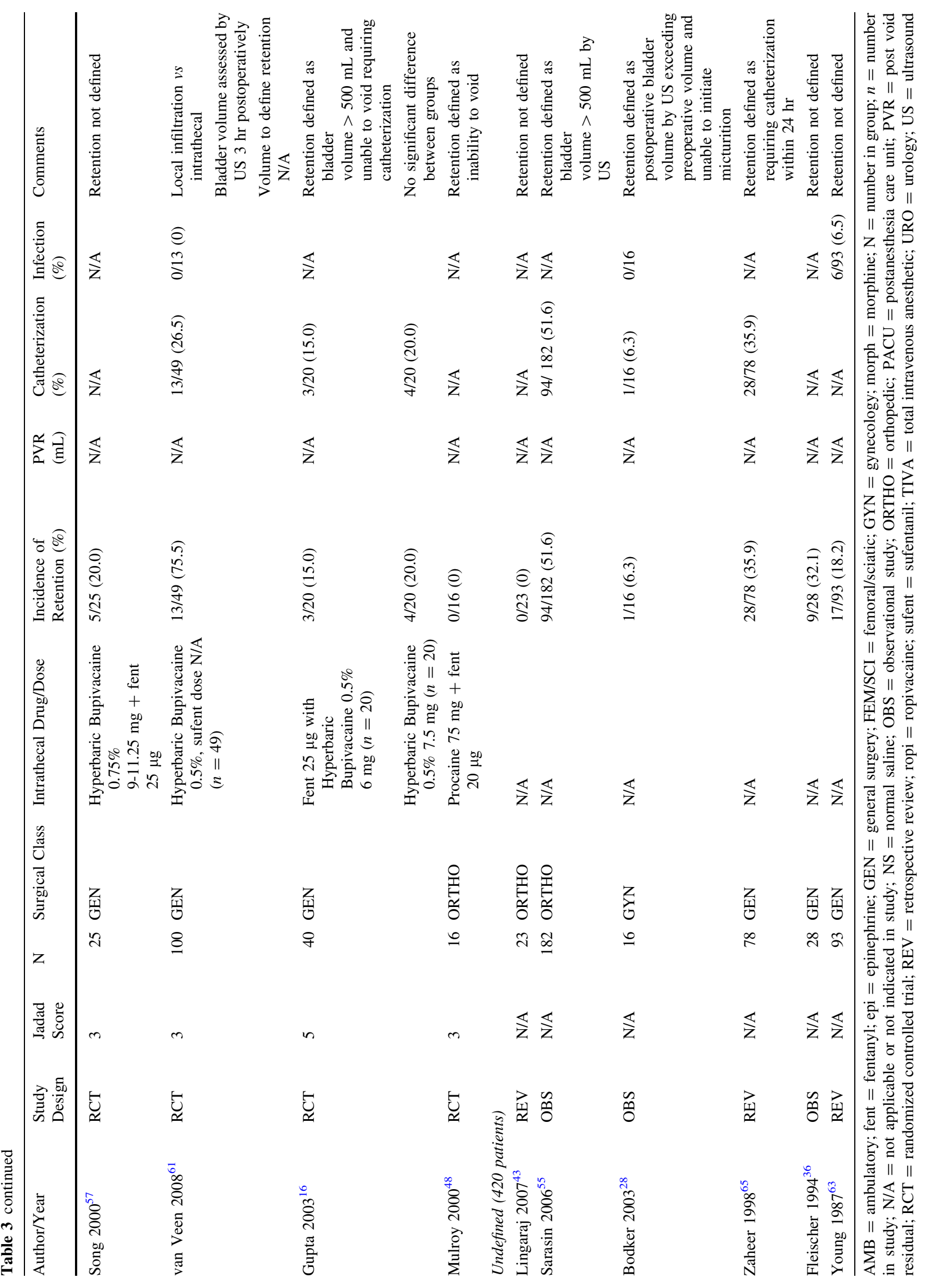




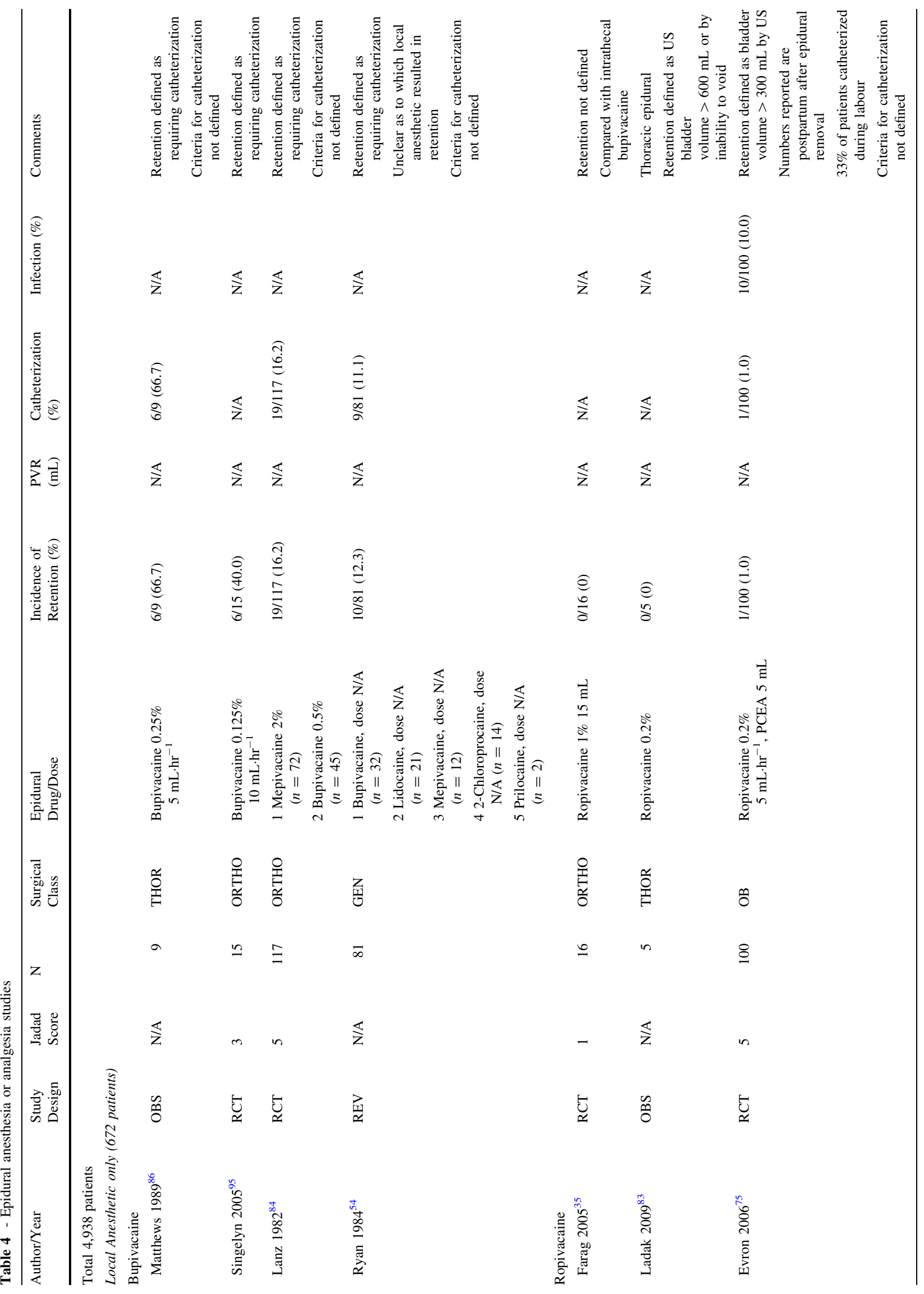




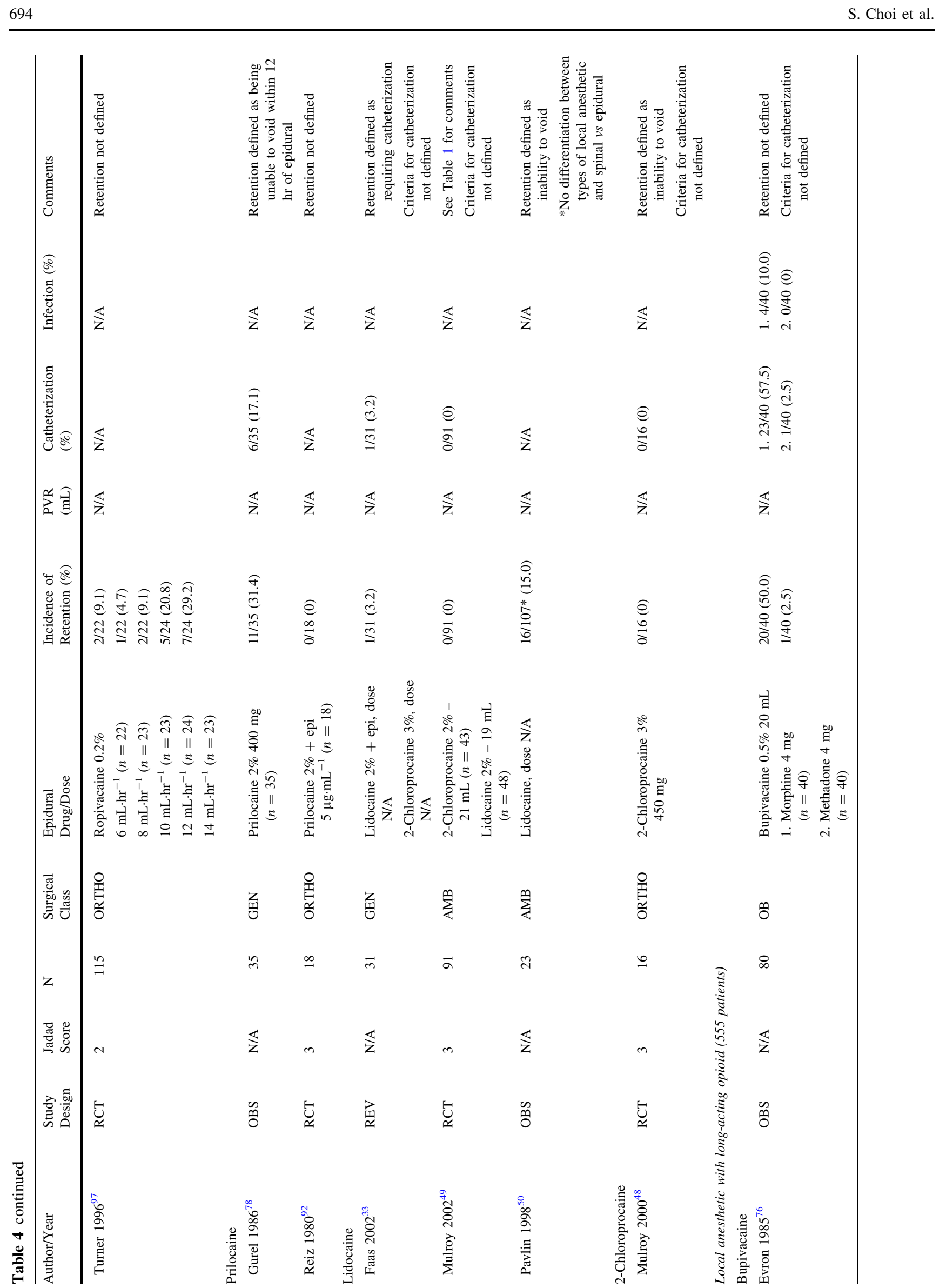

照 Springer 


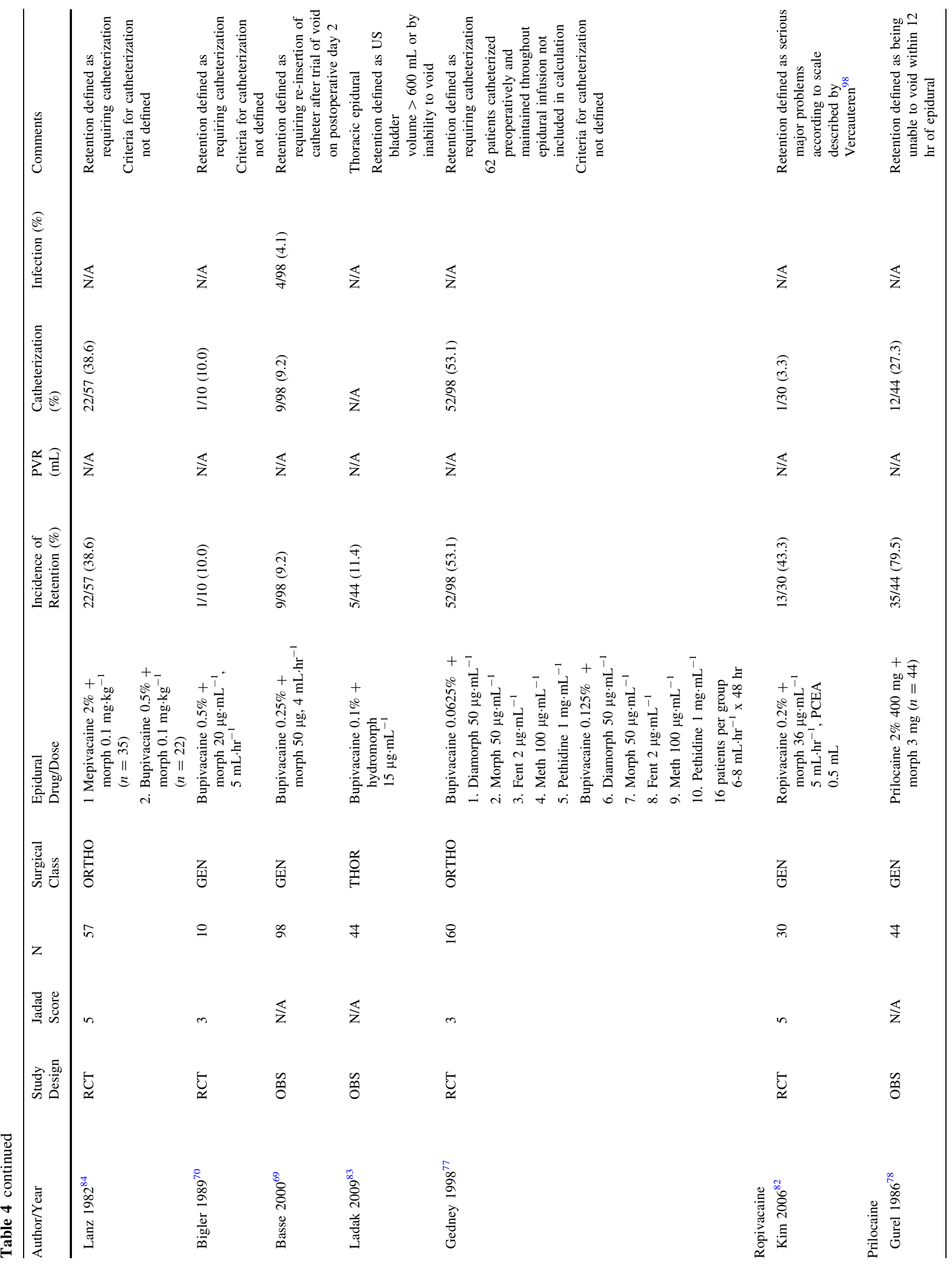




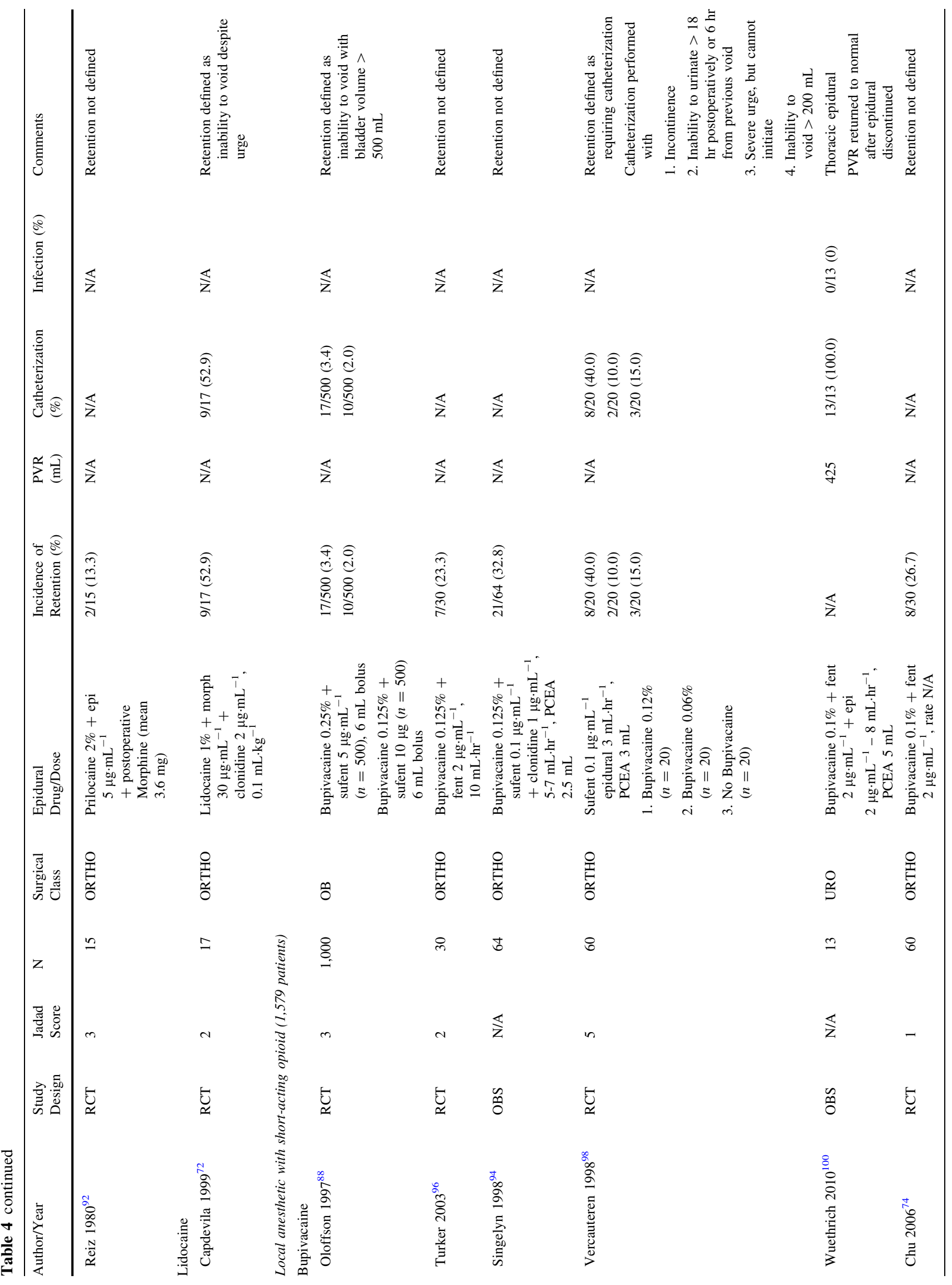


Neuraxial anesthesia and bladder dysfunction

697
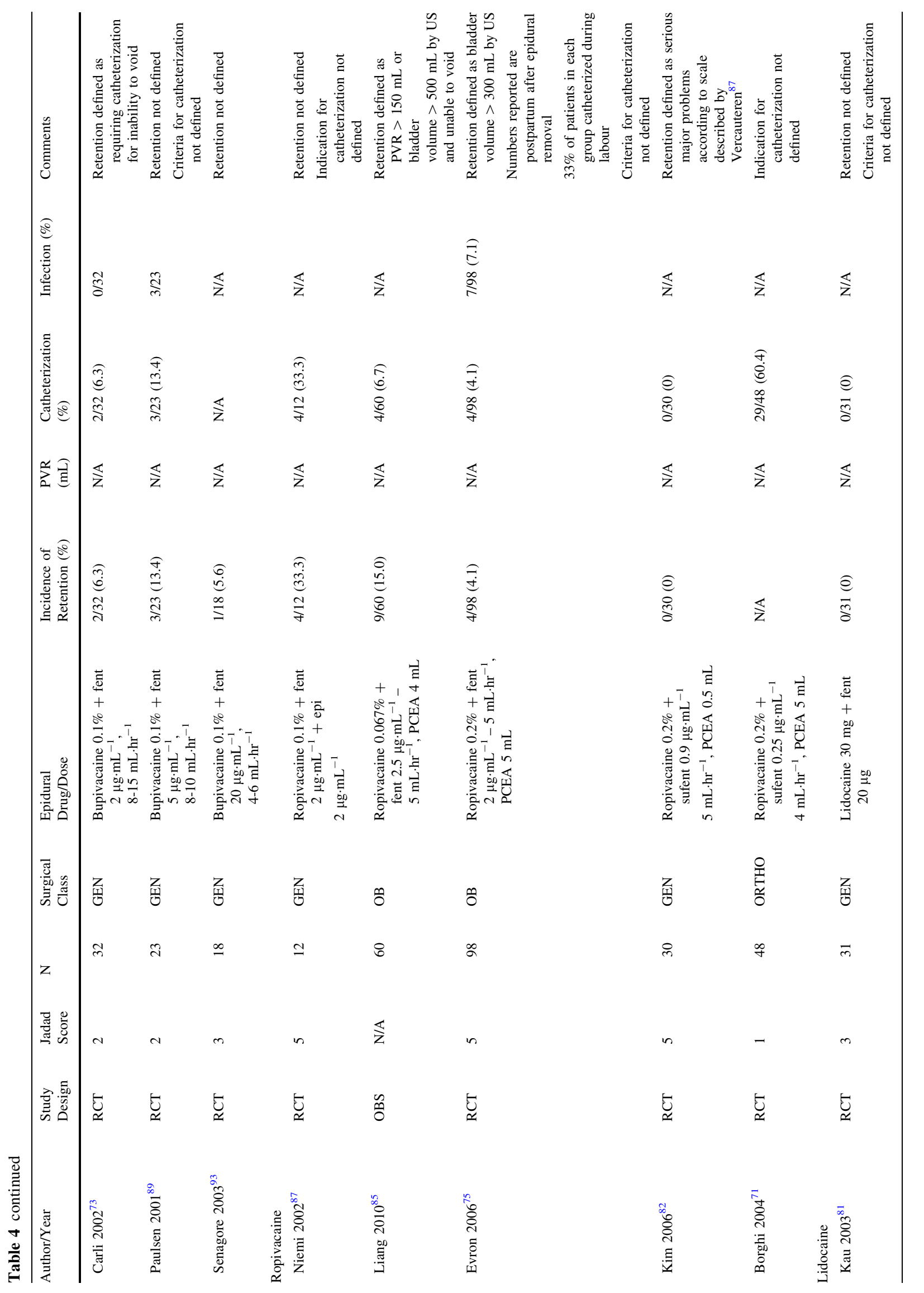

Springer 


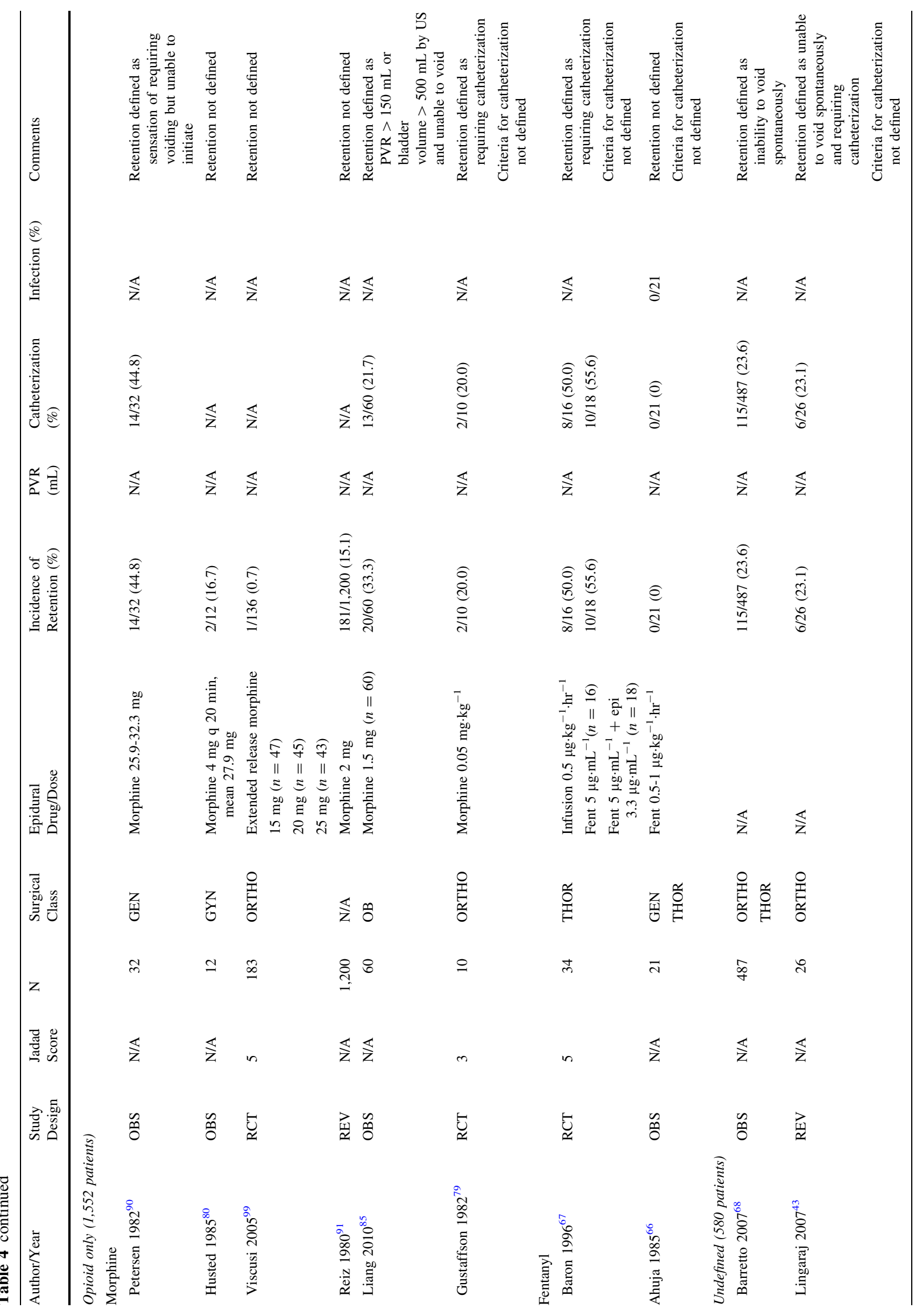


intravesical pressures of $40-50 \mathrm{~cm} \mathrm{H}_{2} \mathrm{O}$ ) did not occur until the block regressed to the S3 segment. Importantly, the mean duration of detrusor block was significantly longer than somatic motor blockade; $233 \mathrm{~min}$ vs $144 \mathrm{~min}$, respectively, for plain lidocaine; $332 \mathrm{~min}$ vs $124 \mathrm{~min}$, respectively, for lidocaine with sufentanil; and $462 \mathrm{~min} v s$ 233 min, respectively, for hyperbaric bupivacaine.

Kuipers et al. studied the dose effect behaviour of isolated intrathecal opiates (sufentanil or morphine) on detrusor function in 40 healthy male volunteers randomized to receive sufentanil ( 10 or $20 \mu \mathrm{g}$ ) or morphine $(0.1$ or $0.3 \mathrm{mg}){ }^{9}$ Urodynamic data, including flow rates, bladder pressures, and post void residuals, were recorded hourly. Typically, administration of opiates resulted in dosedependent decreases in urinary flow rate, increased voiding time, increased post void residual, and diminished urge sensation. Bladder function reverted to normal within $24 \mathrm{hr}$ in all those receiving sufentanil and morphine $0.1 \mathrm{mg}$. Two participants receiving the higher morphine dose $(0.3 \mathrm{mg})$ did not have full recovery of bladder function within the 24-hr study period. The lower dose of sufentanil $(10 \mu \mathrm{g})$ resulted in diminished urge (itself a subjective sensation) in six of ten subjects $v s$ nine of ten when the larger dose was used.

The above urodynamic data show the mechanism of detrusor dysfunction, and our data suggest that it is drug and dose related. It is unclear when detrusor dysfunction becomes POUR, although, regardless of the definitions used by source studies, POUR occurred more frequently with high potency local anesthetics, higher doses, and opioids.

There are other purported risk factors for POUR that were not addressed in this review, including the volume of intraoperative fluid administered, type of surgery, and age. Keita et al. prospectively studied 313 adult patients (mean age $46 \mathrm{yr}$; range 16-88 yr) scheduled for general $(86.5 \%)$ or neuraxial $(13.5 \%)$ anesthesia and showed that the volume of intraoperative fluid administration $(\geq 750 \mathrm{~mL}$ odds ratio $[\mathrm{OR}]=2.3)$, age $(\geq 50 \mathrm{yr}$ OR $=2.4)$, and bladder volume on entry to the postanesthesia care unit $(\geq 270 \mathrm{~mL}$ $\mathrm{OR}=4.8$ ) were independent risk factors for the development of POUR. ${ }^{39}$ Joelsson-Alm et al. observed that orthopedic surgical patients were 6.87 times (95\% confidence interval [CI] 1.76 to 26.79) more likely to develop bladder distension. ${ }^{101}$ Other studies have implicated colorectal surgery and obstetric status as risk factors. The odds ratio for POUR after colorectal surgery and epidural analgesia was reported to be as great as 4.3 (95\% CI 1.2 to 15.9). ${ }^{5}$ Weiniger et al. showed that intrapartum women receiving epidural analgesia during labour had greater post void residuals independent of fluid volume administered when compared with controls not receiving epidural anesthesia (median $240 \mathrm{~mL}$ vs $45 \mathrm{~mL}$, respectively) with 
no significant difference on postpartum days one or two. ${ }^{102}$ In addition, advanced age appears to be a risk factor for urinary retention as males $>70 \mathrm{yr}$ having spinal anesthesia for lower limb joint replacement are at higher risk of developing retention than females or those $<69 \mathrm{yr}$ irrespective of anesthetic modality. ${ }^{55,103}$

\section{Conclusion}

Our review of the literature suggests that the duration of detrusor dysfunction caused by neuraxial anesthesia and analgesia is related to the dose/potency of local anesthetic and the use of long-acting neuraxial opioids. This may influence the incidence of POUR. Unfortunately, the defining criteria in the literature are so heterogeneous when present that an accurate estimate of the incidence and subsequent complications is extremely difficult to determine.

There are several limitations to our review. First, only two of the RCTs included in this review specifically compared general with neuraxial anesthesia and the respective incidence of POUR as a primary outcome, inherently resulting in underpowered results. The observational studies included frequently lacked a comparator group. Second, the definitions of POUR were widely variable such that POUR in one study may not be considered POUR in another. Details regarding individual cases were not provided, preventing any ability to rate outcomes according to standardized criteria.

From the available literature, short-acting neuraxial blockade is safe in both inpatient and ambulatory anesthesia given the short duration of detrusor dysfunction with a minimal incidence of POUR and subsequent catheterization/infection. However, clinicians should select agents carefully to strike a balance between duration of somatic blockade and the risk of POUR. We suggest that clinicians remain cognizant of this issue and scan patients at higher risk of urinary retention with catheterization at a bladder volume of $500 \mathrm{~mL}$ ( cystometric capacity) given that there is a lack of knowledge regarding the subclinical implications of an episode of retention that "spontaneously" resolves.

Moving forward, standard definitions for urinary retention and indications for catheterization should be developed in conjunction with urologists so that relevant clinical trials comparing anesthetic modalities and incorporating urological endpoints produce data that can be easily used by all clinicians to assess and manage this clinical problem.

Acknowledgement The authors sincerely thank Professor Stephen Halpern for his suggestions and input.
Disclosures The authors have no conflicts of interests to declare and they did not receive financial support for this work.

\section{References}

1. Baldini G, Bagry H, Aprikian A, Carli F. Postoperative urinary retention: anesthetic and perioperative considerations. Anesthesiology 2009; 110: 1139-57.

2. Getliffe K. Care of urinary catheters. Nurs Stand 1996; 11 : 47-50.

3. Schaeffer AJ. Catheter-associated bacteriuria. Urol Clin North Am 1986; 13: 735-47.

4. Williams MP, Wallhagen M, Dowling G. Urinary retention in hospitalized elderly women. J Gerontol Nurs 1993; 19: 7-14.

5. Marret E, Remy C, Postoperative Pain Forum Group. Metaanalysis of epidural analgesia versus parenteral opioid analgesia after colorectal surgery. Br J Surg 2007; 94: 665-73.

6. Kaplan SA, Wein AJ, Staskin DR, Roehrborn CG, Steers WD. Urinary retention and post-void residual urine in men: separating truth from tradition. J Urol 2008; 180: 47-54.

7. Bromage PR, Camporesi EM, Durant PA, Nielsen CH. Nonrespiratory side effects of epidural morphine. Anesth Analg 1982; 61: 490-5.

8. Dray A, Metsch R. Inhibition of urinary bladder contractions by a spinal action of morphine and other opioids. J Pharmacol Exp Ther 1984; 231: 254-60.

9. Kuipers PW, Kamphuis ET, van Venrooij GE, et al. Intrathecal opioids and lower urinary tract function: a urodynamic evaluation. Anesthesiology 2004; 100: 1497-503.

10. Jadad AR, Moore RA, Carroll D, et al. Assessing the quality of reports of randomized clinical trials: is blinding necessary? Control Clin Trials 1996; 17: 1-12.

11. Ben-David B, Levin H, Solomon E, Admoni H, Vaida S. Spinal bupivacaine in ambulatory surgery: the effect of saline dilution. Anesth Analg 1996; 83: 716-20.

12. Ben-David B, Maryanovsky M, Gurevitch A, et al. A comparison of minidose lidocaine-fentanyl and conventional-dose lidocaine spinal anesthesia. Anesth Analg 2000; 91: 865-70.

13. Breebaart MB, Vercauteren MP, Hoffmann VL, Adriaensen HA. Urinary bladder scanning after day-case arthroscopy under spinal anaesthesia: comparison between lidocaine, ropivacaine, and levobupivacaine. Br J Anaesth 2003; 90: 309-13.

14. Dijkstra T, Reesink JA, Verdouw BC, Van der Pol WS, Feberwee $T$, Vulto $A G$. Spinal anaesthesia with articaine $5 \%$ vs bupivacaine $0.5 \%$ for day-case lower limb surgery: a double-blind randomized clinical trial. Br J Anaesth 2008; 100: 104-8.

15. Gonter AF, Kopacz DJ. Spinal 2-chloroprocaine: a comparison with procaine in volunteers. Anesth Analg 2005; 100: 573-9.

16. Gupta A, Axelsson K, Thorn SE, et al. Low-dose bupivacaine plus fentanyl for spinal anesthesia during ambulatory inguinal herniorrhaphy: a comparison between $6 \mathrm{mg}$ and $7.5 \mathrm{mg}$ of bupivacaine. Acta Anaesthesiol Scand 2003; 47: 13-9.

17. Hendriks MP, de Weert CJ, Snoeck MM, Hu HP, Pluim MA, Gielen MJ. Plain articaine or prilocaine for spinal anaesthesia in day-case knee arthroscopy: a double-blind randomized trial. Br J Anaesth 2009; 102: 259-63.

18. Kamphuis ET, Kuipers $P W$, van Venrooij GE, Kalkman CJ. The effects of spinal anesthesia with lidocaine and sufentanil on lower urinary tract functions. Anesth Analg 2008; 107: 2073-8.

19. Kawamata YT, Nishikawa K, Kawamata T, et al. A comparison of hyperbaric $1 \%$ and $3 \%$ solutions of small-dose lidocaine in spinal anesthesia. Anesth Analg 2003; 96: 881-4. 
20. Kuusniemi KS, Pihlajamaki KK, Pitkanen MT. A low dose of plain or hyperbaric bupivacaine for unilateral spinal anesthesia. Reg Anesth Pain Med 2000; 25: 605-10.

21. Lacasse MA, Roy JD, Forget J, et al. Comparison of bupivacaine and 2-chloroprocaine for spinal anesthesia for outpatient surgery: a double-blind randomized trial. Can J Anesth 2011; 58: 384-91.

22. Urmey WF, Stanton J, Peterson M, Sharrock NE. Combined spinal-epidural anesthesia for outpatient surgery. Dose-response characteristics of intrathecal isobaric lidocaine using a 27-gauge Whitacre spinal needle. Anesthesiology 1995; 83: 528-34.

23. Valanne JV, Korhonen AM, Jokela RM, Ravaska P, Korttila KK. Selective spinal anesthesia: a comparison of hyperbaric bupivacaine $4 \mathrm{mg}$ versus $6 \mathrm{mg}$ for outpatient knee arthroscopy. Anesth Analg 2001; 93: 1377-9.

24. Yoos JR, Kopacz DJ. Spinal 2-chloroprocaine: a comparison with small-dose bupivacaine in volunteers. Anesth Analg 2005; 100: 566-72.

25. Casati A, Danelli G, Berti M, et al. Intrathecal 2-chloroprocaine for lower limb outpatient surgery: a prospective, randomized, double-blind, clinical evaluation. Anesth Analg 2006; 103: 234-8.

26. Kallio H, Snall EV, Luode T, Rosenberg PH. Hyperbaric articaine for day-case spinal anaesthesia. Br J Anaesth 2006; 97 : 704-9.

27. Anannamcharoen $S$, Cheeranont $P$, Boonya-usadon $C$. Local perianal nerve block versus spinal block for closed hemorrhoidectomy: a ramdomized controlled trial. J Med Assoc Thai 2008; 91: 1862-6.

28. Bodker B, Lose G. Postoperative urinary retention in gynecologic patients. Int Urogynecol J Pelvic Floor Dysfunct 2003; 14: 94-7.

29. Borghi B, Stagni F, Bugamelli $S$, et al. Unilateral spinal block for outpatient knee arthroscopy: a dose-finding study. J Clin Anesth 2003; 15: 351-6.

30. Carpiniello VL, Cendron M, Altman HG, Malloy TR, Booth $R$. Treatment of urinary complications after total joint replacement in elderly females. Urology 1988; 32: 186-8.

31. Casati A, Cappelleri G, Aldegheri G, Marchetti C, Messina M, De Ponti A. Total intravenous anesthesia, spinal anesthesia or combined sciatic-femoral nerve block for outpatient knee arthroscopy. Minerva Anestesiol 2004; 70: 493-502.

32. Esmaoglu A, Karaoglu S, Mizrak A, Boyaci A. Bilateral vs. unilateral spinal anesthesia for outpatient knee arthroscopies. Knee Surg Sports Traumatol Arthrosc 2004; 12: 155-8.

33. Faas CL, Acosta FJ, Campbell MD, O'Hagan CE, Newton SE, Zagalaniczny $K$. The effects of spinal anesthesia vs epidural anesthesia on 3 potential postoperative complications: pain, urinary retention, and mobility following inguinal herniorrhaphy. AANA J 2002; 70: 441-7.

34. Fanelli G, Borghi B, Casati A, Bertini L, Montebugnoli M, Torri $G$. Unilateral bupivacaine spinal anesthesia for outpatient knee arthroscopy. Italian Study Group on Unilateral Spinal Anesthesia. Can J Anesth 2000; 47: 746-51.

35. Farag E, Dilger J, Brooks P, Tetzlaff JE. Epidural analgesia improves early rehabilitation after total knee replacement. J Clin Anesth 2005; 17: 281-5.

36. Fleischer M, Marini CP, Statman R, Capella J, Shevde K. Local anesthesia is superior to spinal anesthesia for anorectal surgical procedures. Am Surg 1994; 60: 812-5.

37. Jellish WS, Thalji Z, Stevenson K, Shea J. A prospective randomized study comparing short- and intermediate-term perioperative outcome variables after spinal or general anesthesia for lumbar disk and laminectomy surgery. Anesth Analg 1996; 83: 559-64.
38. Kaya M, Oguz S, Aslan K, Kadiogullari N. A low-dose bupivacaine: a comparison of hyperbaric and hypobaric solutions for unilateral spinal anesthesia. Reg Anesth Pain Med 2004; 29: 17-22.

39. Keita H, Diouf E, Tubach F, et al. Predictive factors of early postoperative urinary retention in the postanesthesia care unit. Anesth Analg 2005; 101: 592-6.

40. Kreutziger J, Frankenberger B, Luger TJ, Richard S, Zbinden S. Urinary retention after spinal anaesthesia with hyperbaric prilocaine $2 \%$ in an ambulatory setting. Br J Anaesth 2010; 104: 582-6.

41. Lamonerie L, Marret E, Deleuze A, Lembert N, Dupont M, Bonnet $F$. Prevalence of postoperative bladder distension and urinary retention detected by ultrasound measurement. $\mathrm{Br} \mathbf{J}$ Anaesth 2004; 92: 544-6.

42. Linares Gil MJ, Esteve Gomez A, Blanco Vargas D, et al. Factors associated with delayed postsurgical voiding interval in ambulatory spinal anesthesia patients: a prospective cohort study in 3 types of surgery. Am J Surg 2009; 197: 182-8.

43. Lingaraj K, Ruben M, Chan YH, Das SD. Identification of risk factors for urinary retention following total knee arthroplasty: a Singapore hospital experience. Singapore Med J 2007; 48: 213-6.

44. Luger TJ, Garoscio I, Rehder P, Oberladstatter J, Voelckel W. Management of temporary urinary retention after arthroscopic knee surgery in low-dose spinal anesthesia: development of a simple algorithm. Arch Orthop Trauma Surg 2008; 128: 607-12.

45. Mahan KT, Wang J. Spinal morphine anesthesia and urinary retention. J Am Podiatr Med Assoc 1993; 83: 607-14.

46. McLain RF, Kalfas I, Bell GR, Tetzlaff JE, Yoon HJ, Rana M. Comparison of spinal and general anesthesia in lumbar laminectomy surgery: a case-controlled analysis of 400 patients. J Neurosurg Spine 2005; 2: 17-22.

47. Moreno-Egea A, Aguayo JL, Vicente JP, Cartagena J, Sanz J. General vs regional anaesthesia in outpatient treatment for inguinal hernias using extraperitoneal laparoscopy. Hernia 2000; 4: 135-9.

48. Mulroy MF, Larkin KL, Hodgson PS, Helman JD, Pollock JE, Liu SS. A comparison of spinal, epidural, and general anesthesia for outpatient knee arthroscopy. Anesth Analg 2000; 91: 860-4.

49. Mulroy MF, Salinas FV, Larkin KL, Polissar NL. Ambulatory surgery patients may be discharged before voiding after shortacting spinal and epidural anesthesia. Anesthesiology 2002; 97: 315-9.

50. Pavlin DJ, Rapp SE, Polissar NL, Malmgren JA, Koerschgen M, Keyes $H$. Factors affecting discharge time in adult outpatients. Anesth Analg 1998; 87: 816-26.

51. Pawlowski J, Sukhani R, Pappas AL, et al. The anesthetic and recovery profile of two doses $(60$ and $80 \mathrm{mg}$ ) of plain mepivacaine for ambulatory spinal anesthesia. Anesth Analg 2000; 91 : 580-4.

52. Petros JG, Bradley TM. Factors influencing postoperative urinary retention in patients undergoing surgery for benign anorectal disease. Am J Surg 1990; 159: 374-6.

53. Petros JG, Rimm EB, Robillard RJ, Argy O. Factors influencing postoperative urinary retention in patients undergoing elective inguinal herniorrhaphy. Am J Surg 1991; 161: 431-3.

54. Ryan JA Jr, Adye BA, Jolly PC, Mulroy MF 2nd. Outpatient inguinal herniorrhaphy with both regional and local anesthesia. Am J Surg 1984; 148: 313-6.

55. Sarasin SM, Walton MJ, Singh HP, Clark DI. Can a urinary tract symptom score predict the development of postoperative urinary retention in patients undergoing lower limb arthroplasty under spinal anaesthesia? A prospective study. Ann R Coll Surg Engl 2006; 88: 394-8. 
56. Schmittner MD, Schreiber H, Janke A, et al. Randomized clinical trial of perianal surgery performed under spinal saddle block versus total intravenous anaesthesia. Br J Surg 2010; 97: 12-20.

57. Song D, Greilich NB, White PF, Watcha MF, Tongier WK. Recovery profiles and costs of anesthesia for outpatient unilateral inguinal herniorrhaphy. Anesth Analg 2000; 91: 876-81.

58. Sungurtekin H, Sungurtekin U, Erdem E. Local anesthesia and midazolam versus spinal anesthesia in ambulatory pilonidal surgery. J Clin Anesth 2003; 15: 201-5.

59. Toyonaga T, Matsushima M, Sogawa N, et al. Postoperative urinary retention after surgery for benign anorectal disease: potential risk factors and strategy for prevention. Int J Colorectal Dis 2006; 21: 676-82.

60. Urmey WF, Stanton J, Bassin P, Sharrock NE. The direction of the Whitacre needle aperture affects the extent and duration of isobaric spinal anesthesia. Anesth Analg 1997; 84: 337-41.

61. van Veen RN, Mahabier C, Dawson I, et al. Spinal or local anesthesia in lichtenstein hernia repair: a randomized controlled trial. Ann Surg 2008; 247: 428-33.

62. Voelckel WG, Kirchmair L, Rehder P, Garoscio I, Krappinger $D$, Luger TJ. Unilateral anesthesia does not affect the incidence of urinary retention after low-dose spinal anesthesia for knee surgery. Anesth Analg 2009; 109: 986-7.

63. Young DV. Comparison of local, spinal, and general anesthesia for inguinal herniorrhaphy. Am J Surg 1987; 153: 560-3.

64. Zacharoulis D, Fafoulakis F, Baloyiannis I, et al. Laparoscopic transabdominal preperitoneal repair of inguinal hernia under spinal anesthesia: a pilot study. Am J Surg 2009; 198: 456-9.

65. Zaheer S, Reilly WT, Pemberton JH, Ilstrup D. Urinary retention after operations for benign anorectal diseases. Dis Colon Rectum 1998; 41: 696-704.

66. Ahuja BR, Strunin L. Respiratory effects of epidural fentanyl. Changes in end-tidal $\mathrm{CO} 2$ and respiratory rate following single doses and continuous infusions of epidural fentanyl. Anaesthesia 1985; 40: 949-55.

67. Baron CM, Kowalski SE, Greengrass $R$, Horan TA, Unruh HW, Baron $C L$. Epinephrine decreases postoperative requirements for continuous thoracic epidural fentanyl infusions. Anesth Analg 1996; 82: 760-5.

68. Barretto de Carvalho Fernandes Mdo C, Vieira da Costa V, Saraiva $R A$. Postoperative urinary retention: evaluation of patients using opioids analgesic. Rev Lat Am Enfermagem 2007; 15: 318-22.

69. Basse $L$, Werner $M$, Kehlet $H$. Is urinary drainage necessary during continuous epidural analgesia after colonic resection? Reg Anesth Pain Med 2000; 25: 498-501.

70. Bigler D, Dirkes W, Hansen R, Rosenberg J, Kehlet $H$. Effects of thoracic paravertebral block with bupivacaine versus combined thoracic epidural block with bupivacaine and morphine on pain and pulmonary function after cholecystectomy. Acta Anaesthesiol Scand 1989; 33: 561-4.

71. Borghi B, Agnoletti V, Ricci A, van Oven H, Montone N, Casati $A$. A prospective, randomized evaluation of the effects of epidural needle rotation on the distribution of epidural block. Anesth Analg 2004; 98: 1473-8.

72. Capdevila X, Barthelet $Y$, Biboulet P, Ryckwaert Y, Rubenovitch $J, d^{\prime}$ 'Athis $F$. Effects of perioperative analgesic technique on the surgical outcome and duration of rehabilitation after major knee surgery. Anesthesiology 1999; 91: 8-15.

73. Carli F, Mayo N, Klubien K, Schricker T, Trudel J, Belliveau P. Epidural analgesia enhances functional exercise capacity and health-related quality of life after colonic surgery: results of a randomized trial. Anesthesiology 2002; 97: 540-9.

74. Chu CP, Yap JC, Chen PP, Hung HH. Postoperative outcome in Chinese patients having primary total knee arthroplasty under general anaesthesia/intravenous patient-controlled analgesia compared to spinal-epidural anaesthesia/analgesia. Hong Kong Med J 2006; 12: 442-7.

75. Evron S, Muzikant G, Rigini N, et al. Patient-controlled epidural analgesia: the role of epidural fentanyl in peripartum urinary retention. Int J Obstet Anesth 2006; 15: 206-11.

76. Evron S, Samueloff A, Simon A, Drenger B, Magora F. Urinary function during epidural analgesia with methadone and morphine in post-cesarean section patients. Pain 1985; 23: 135-44.

77. Gedney JA, Liu EH. Side-effects of epidural infusions of opioid bupivacaine mixtures. Anaesthesia 1998; 53: 1148-55.

78. Gurel A, Unal N, Elevli M, Eren A. Epidural morphine for postoperative pain relief in anorectal surgery. Anesth Analg 1986; 65: 499-502.

79. Gustafsson LL, Friberg-Nielsen S, Garle M, et al. Extradural and parenteral morphine: kinetics and effects in postoperative pain. A controlled clinical study. Br J Anaesth 1982; 54: 1167-74.

80. Husted S, Djurhuus JC, Husegaard HC, Jepsen J, Mortensen J. Effect of postoperative extradural morphine on lower urinary tract function. Acta Anaesthesiol Scand 1985; 29: 183-5.

81. Kau YC, Lee YH, Li JY, Chen C, Wong SY, Wong TK. Epidural anesthesia does not increase the incidences of urinary retention and hesitancy in micturition after ambulatory hemorrhoidectomy. Acta Anaesthesiol Sin 2003; 41: 61-4.

82. Kim JY, Lee SJ, Koo BN, et al. The effect of epidural sufentanil in ropivacaine on urinary retention in patients undergoing gastrectomy. Br J Anaesth 2006; 97: 414-8.

83. Ladak SS, Katznelson R, Muscat M, Sawhney M, Beattie WS, $O$ 'Leary $G$. Incidence of urinary retention in patients with thoracic patient-controlled epidural analgesia (TPCEA) undergoing thoracotomy. Pain Manag Nurs 2009; 10: 94-8.

84. Lanz E, Theiss D, Riess W, Sommer U. Epidural morphine for postoperative analgesia: a double-blind study. Anesth Analg 1982; 61: 236-40.

85. Liang CC, Chang SD, Wong SY, Chang YL, Cheng PJ. Effects of postoperative analgesia on postpartum urinary retention in women undergoing cesarean delivery. J Obstet Gynaecol Res 2010; 36: 991-5.

86. Matthews PJ, Govenden V. Comparison of continuous paravertebral and extradural infusions of bupivacaine for pain relief after thoracotomy. Br J Anaesth 1989; 62: 204-5.

87. Niemi $G$, Breivik $H$. Epinephrine markedly improves thoracic epidural analgesia produced by a small-dose infusion of ropivacaine, fentanyl, and epinephrine after major thoracic or abdominal surgery: a randomized, double-blinded crossover study with and without epinephrine. Anesth Analg 2002; 94: 1598-605.

88. Olofsson CI, Ekblom AO, Ekman-Ordeberg GE, Irestedt LE. Post-partum urinary retention: a comparison between two methods of epidural analgesia. Eur J Obstet Gynecol Reprod Biol 1997; 71: 31-4.

89. Paulsen EK, Porter MG, Helmer SD, Linhardt PW, Kliewer ML. Thoracic epidural versus patient-controlled analgesia in elective bowel resections. Am J Surg 2001; 182: 570-7.

90. Petersen TK, Husted SE, Rybro L, Schurizek BA, Wernberg M. Urinary retention during i.m. and extradural morphine analgesia. Br J Anaesth 1982; 54: 1175-8.

91. Reiz S, Ahlin J, Ahrenfeldt B, Andersson M, Andersson S. Epidural morphine for postoperative pain relief. Acta Anaesthesiol Scand 1981; 25: 111-4.

92. Reiz S, Westberg M. Side-effects of epidural morphine. Lancet 1980; 2: 203-4.

93. Senagore AJ, Delaney CP, Mekhail N, Dugan A, Fazio VW. Randomized clinical trial comparing epidural anaesthesia and patient-controlled analgesia after laparoscopic segmental colectomy. Br J Surg 2003; 90: 1195-9. 
94. Singelyn FJ, Deyaert M, Joris D, Pendeville E, Gouverneur JM. Effects of intravenous patient-controlled analgesia with morphine, continuous epidural analgesia, and continuous three-inone block on postoperative pain and knee rehabilitation after unilateral total knee arthroplasty. Anesth Analg 1998; 87: 88-92.

95. Singelyn FJ, Ferrant T, Malisse MF, Joris D. Effects of intravenous patient-controlled analgesia with morphine, continuous epidural analgesia, and continuous femoral nerve sheath block on rehabilitation after unilateral total-hip arthroplasty. Reg Anesth Pain Med 2005; 30: 452-7.

96. Turker G, Uckunkaya N, Yavascaoglu B, Yilmazlar A, Ozcelik S. Comparison of the catheter-technique psoas compartment block and the epidural block for analgesia in partial hip replacement surgery. Acta Anaesthesiol Scand 2003; 47: 30-6.

97. Turner $G$, Blake D, Buckland $M$, et al. Continuous extradural infusion of ropivacaine for prevention of postoperative pain after major orthopaedic surgery. Br J Anaesth 1996; 76: 606-10.

98. Vercauteren MP, Van Den Bergh L, Kartawiadi SL, Van Boxem $K$, Hoffmann $V L$. Addition of bupivacaine to sufentanil in patient-controlled epidural analgesia after lower limb surgery in young adults: effect on analgesia and micturition. Reg Anesth Pain Med 1998; 23: 182-8.

99. Viscusi ER, Martin G, Hartrick CT, Singla N, EREM Study Group. Forty-eight hours of postoperative pain relief after total hip arthroplasty with a novel, extended-release epidural morphine formulation. Anesthesiology 2005; 102: 1014-22.

100. Wuethrich PY, Kessler TM, Panicker JN, Curatolo M, Burkhard $F C$. Detrusor activity is impaired during thoracic epidural analgesia after open renal surgery. Anesthesiology 2010; 112: 1345-9.

101. Joelsson-Alm E, Nyman CR, Lindholm C, Ulfvarson J, Svensen $C$. Perioperative bladder distension: a prospective study. Scand $\mathrm{J}$ Urol Nephrol 2009; 43: 58-62.

102. Weiniger $C F$, Wand $S$, Nadjari $M$, et al. Post-void residual volume in labor: a prospective study comparing parturients with and without epidural analgesia. Acta Anaesthesiol Scand 2006; 50: 1297-303.

103. Kotwal R, Hodgson $P$, Carpenter $C$. Urinary retention following lower limb arthroplasty: analysis of predictive factors and review of literature. Acta Orthop Belg 2008; 74: 332-6. 